\title{
An Experimental Investigation into Chosen Parameters of Diesel-Water Emulsion on Combustion Processes
}

\author{
Pradeep Kumar Arokiasamy Remigious, Annamalai Kandasamy, and \\ Premkartikkumar Selvi Rajaram
}

Department of Automobile Engineering, Anna University, MIT Campus, Chennai, India

Correspondence should be addressed to Pradeep Kumar Arokiasamy Remigious; dearpradeepkumar@gmail.com

Received 31 May 2013; Revised 18 July 2013; Accepted 30 July 2013

Academic Editor: João Paulo Leal

Copyright ( 2013 Pradeep Kumar Arokiasamy Remigious et al. This is an open access article distributed under the Creative Commons Attribution License, which permits unrestricted use, distribution, and reproduction in any medium, provided the original work is properly cited.

\begin{abstract}
The purpose of this research is to investigate the effect of mixing water with diesel to make an emulsified fuel considering the needs for the vehicle performance and its cleanest possible operation. The test fuels chosen for the investigation are termed Emulsion 1 (EM1) and Emulsion 2 (EM2). EM1 is prepared in the ratio of 91/8/1 which represents $91 \%$ diesel, $8 \%$ water, $0.5 \%$ surfactant (Span 20 ), and $0.5 \%$ cosurfactant (Tween 20 ) with continuous stirring. EM2 has a composition of $94 \%$ diesel, $5 \%$ water, $0.5 \%$ Span 20 , and $0.5 \%$ Tween 20. The stability of the emulsified fuel is checked for 8 hours. The performance and emission characteristics of EM1 and EM2 are compared with diesel fuel. The emission parameters such as hydrocarbon emission, carbon monoxide (CO) emission, smoke opacity, and oxides of nitrogen $\left(\mathrm{NO}_{x}\right)$ emission have been measured. To compare the difference in performance characteristics between diesel fuel and emulsified fuel, brake thermal efficiency has been taken into account as a measure. Appreciable reductions of emission parameters have been obtained, and hence the investigation assures that this research could be further extended to biodiesel fuel as it produces more $\mathrm{NO}_{x}$ than diesel fuel.
\end{abstract}

\section{Introduction}

Increasing environmental issues and growth of global warming day by day are the driving forces for the researchers to arrive at a clean burning fuel. Fossil fuels cause various environment problems such as acid precipitation, ozone depletion, and global warming, As discussed elsewhere [1-3], for many years, it is recognized that for simultaneous reduction of $\mathrm{NO}_{x}$ and smoke, water in fuel emissions are effective. There are a few researches about the in-cylinder water injection also. It was stated by Chadwell et al. [4] that in-cylinder water injection was successful in reducing oxides of nitrogen emission but not smoke opacity. Moreover, emulsified fuel is a substitute to the diesel without major modification in the diesel engine. A study by Kannan and Udayakumar [5] showed that the main pollutants from diesel engines are $\mathrm{NO}_{x}$ and particulate matter (PM). Ghojel et al. [6] found that the mechanism of formation of $\mathrm{NO}_{x}$ and particulate matter during combustion is contradictory and reducing simultaneously $\mathrm{NO}_{x}$ and smoke is very difficult. During the combustion, explosion of microdroplets of water takes place due to the high pressure and temperature inside the cylinder. This helps in assisting smoother combustion and reduction in oxides of nitrogen emission. The appearance of the dieselwater emulsion is similar to milk and the colour is white. It is due to the presence of microdroplets of water in the diesel. The advantage of the diesel-water emulsion is that it does not contain ionic or toxic surfactant nor metallic additives. Emulsified fuel reduces the diesel's major regulated pollutant, oxides of nitrogen $\left(\mathrm{NO}_{x}\right)$ emission, and does not affect the concentration of unregulated pollutants such as aldehydes and ketones. Armas et al. [7] have stated in his research findings that water emulsified diesel absorbs the heat by water vaporization and causes a decrease in adiabatic flame temperature and therefore reduces chemical reaction in gas phase to produce thermal NO. In an experimental work, Sudrajad et al. [8] have found that the high flame temperature is the major source of thermal NO production. Since the explosion of microdroplets of water suppresses the chemical reaction, the flame temperature gets reduced, and hence there is significant reduction in the production of NO. 
TABLE 1: Comparison of properties of fuel.

\begin{tabular}{llccc}
\hline S. number & Property & Diesel & EM 1 & EM 2 \\
\hline 1 & Density, $\mathrm{kg} / \mathrm{m}^{3}$ & 830 & 833 & 831 \\
2 & Calorific value, $\mathrm{MJ} / \mathrm{kg}$ & 43.2 & 39.3 & 40.9 \\
\hline
\end{tabular}

In this experimental investigation, the various emission parameters such as hydrocarbon emission, carbon monoxide (CO) emission, smoke opacity emission and oxides of nitrogen emission were measured. To compare the variation in the performance characteristics, brake thermal efficiency has been calculated and compared with the reference fuel (petroleum diesel).

\section{Preparation of Diesel-Water Emulsion}

Emulsions are classified into water in oil emulsion and oil in water emulsion. Diesel-water emulsion comes under the category of water in oil emulsion. For the preparation of diesel-water emulsion, the surfactant should be so chosen that it has hydrophile-lipophile balance HLB value in the range of 7 to 11 . If a single surfactant does not satisfy the requirement, a mixed surfactant could be used. Hence in this experimental work, a mixed surfactant is used. As stated by Ghannam and Selim [9], the surfactant's role is to reduce the interfacial tension between the water phase and diesel fuel phase. According to Sherman [10], another role is to stabilize the status of water droplet phase within diesel fuel phase to avoid coalescence mechanism of the water phase. As discussed by Jankowski [11], the surfactant package contains a mixture of two surfactants. He also stated that one of them is a lipophilic surfactant, such as fatty acid. another surfactant was hydrophilic, such as the ionized form of the fatty acid.

After a few trials in checking the stability of the emulsified fuel, two different compositions were taken as test fuels to compare the performance and emission parameters with petroleum diesel. The first composition was termed EM 1 which has a composition of $91 \%$ diesel, $8 \%$ water, $0.5 \%$ Tween 20 and $0.5 \%$ Span 20. Another test fuel has been termed EM 2 which has a composition of $94 \%$ diesel, $5 \%$ water, $0.5 \%$ Tween 20 and $0.5 \%$ Span 20 . The mixing speed ranges from $5000 \mathrm{rpm}$ to $10000 \mathrm{rpm}$ for duration of 10 minutes to get the stability.

\section{Comparison of Fuel Properties}

Initially properties were checked and compared with diesel fuel before carrying out the experimental investigation. Table 1 shows the fuel properties of the reference fuel (Diesel) and the test fuels EM 1 and EM 2. It is observed that addition of water slightly lowers the calorific value and increases the density of emulsified fuel when compared to diesel.

\section{Experimental Setup}

Figure 1 shows the experimental setup used for this investigation. A kirloskar SV1 model, single cylinder water cooled engine, has been used for this experimental investigation.

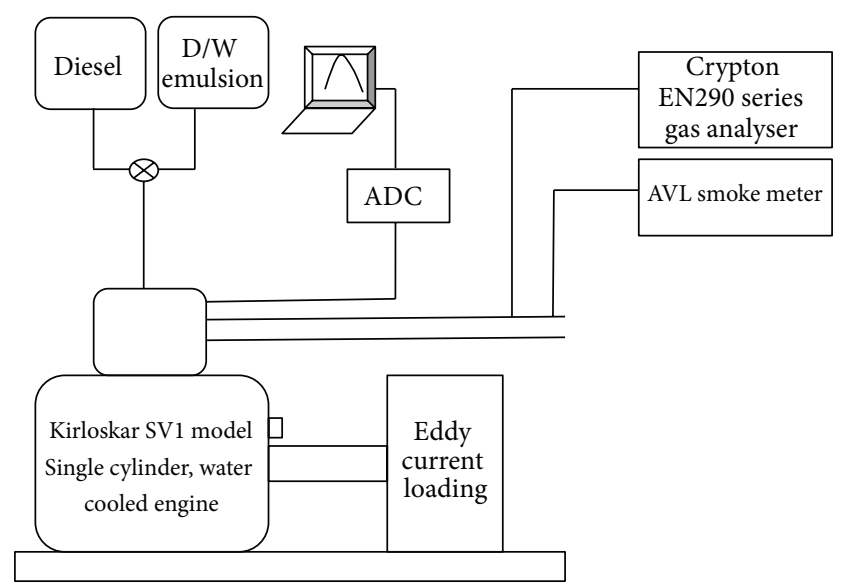

FIgURE 1: Experimental setup. ADC: analog-to-digital converter; D/W emulsion: diesel-water emulsion.

TABLE 2: Engine specification.

\begin{tabular}{lc}
\hline & Engine specification \\
\hline Make and model & Kirloskar, SV1 \\
Type & Vertical \\
Number of strokes & 4 \\
Number of cylinders & 1 \\
Swept volume, cc & 661 \\
Clearance volume, cc & 37.8 \\
Bore, mm & 87.5 \\
Stroke, mm & 110 \\
Rated speed, rpm & 1800 \\
Rated output, kW & 5.9 \\
Shape of combustion chamber & Hemispherical \\
\hline
\end{tabular}

AVL smoke meter which measures the smoke in Hatridge Smoke Units (HSU) was attached to the exhaust pipe. The in-cylinder pressure was measured by Kistler piezoelectric pressure transducer, which fed the data to the data acquisition system. Table 2 shows the technical specification of the test engine.

A high speed type eddy current electric brake dynamometer was used for applying the load to the engine. Exhaust gas temperature was measured with chromel-alumel ( $\mathrm{K}$ type) thermocouple. Type $\mathrm{K}$ thermocouples were used for measuring temperatures upto $1250^{\circ} \mathrm{C}$. Oxides of nitrogen $\left(\mathrm{NO}_{x}\right)$ were measured through a chemical sensor (catalyst) fitted adjacently to the oxygen sensor.

\section{Ranges of the Measuring Equipments Used}

Table 3 shows the measuring range of Crypton EN290 series gas analyser. For measuring AVL 437 smoke meter was used, which measures smoke in the range of 0 to $100 \mathrm{HSU}$ (Hatridge smoke units). The smoke meter works on light absorption principle. 
TABLE 3: Range of Crypton EN290 series gas analyser.

\begin{tabular}{lc}
\hline Gas & Range \\
\hline $\mathrm{NO}_{x}$ & 0 to $5000 \mathrm{ppm}$ \\
$\mathrm{CO}_{2}$ & 0 to $20 \%$ \\
$\mathrm{CO}$ & 0 to $10 \%$ \\
$\mathrm{HC}$ & 0 to $10000 \mathrm{ppm}$ \\
\hline
\end{tabular}

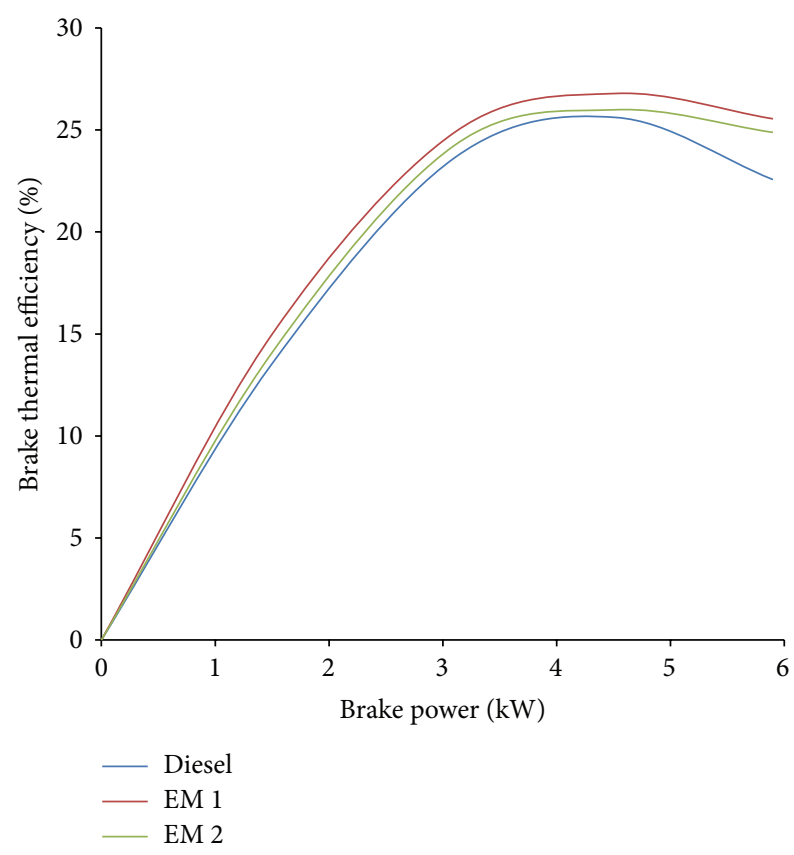

FIGURE 2: Brake power versus brake thermal efficiency.

\section{Results and Discussion}

\subsection{Performance Parameter}

6.1.1. Brake Thermal Efficiency. Figure 2 shows that the brake thermal efficiency increases for both diesel and diesel-water emulsion till three-fourth of load condition, and it is maximum at that point. It reduces when the load is further increased. The diesel-water emulsion shows higher efficiency than petroleum fuel. In a previous research by Kannan and Udayakumar [5], it was discussed that the higher efficiency might be due to the water presence in the emulsion, increased expansion work, and reduced compression thereby increasing the network done during the cycle. He also stated that the increase done in the network and decrease in fuel consumption caused higher brake thermal efficiency. Ghojel et al. [6] carried out their investigation using a heavy duty industrial diesel engine and reported that diesel-water emulsion showed somewhat higher brake thermal efficiency over the diesel. Armas et al. [7] conducted the investigation using an IDI diesel engine and stated that the brake thermal efficiency was better with emulsified fuel, at certain operating conditions. In this experimental investigation increase of $4.59 \%$ and $2.48 \%$ of brake thermal efficiency was observed for the test fuels EM 1 and EM 2, respectively. Though the calorific value is lesser in emulsified fuel due to micro explosion, the energy extracted

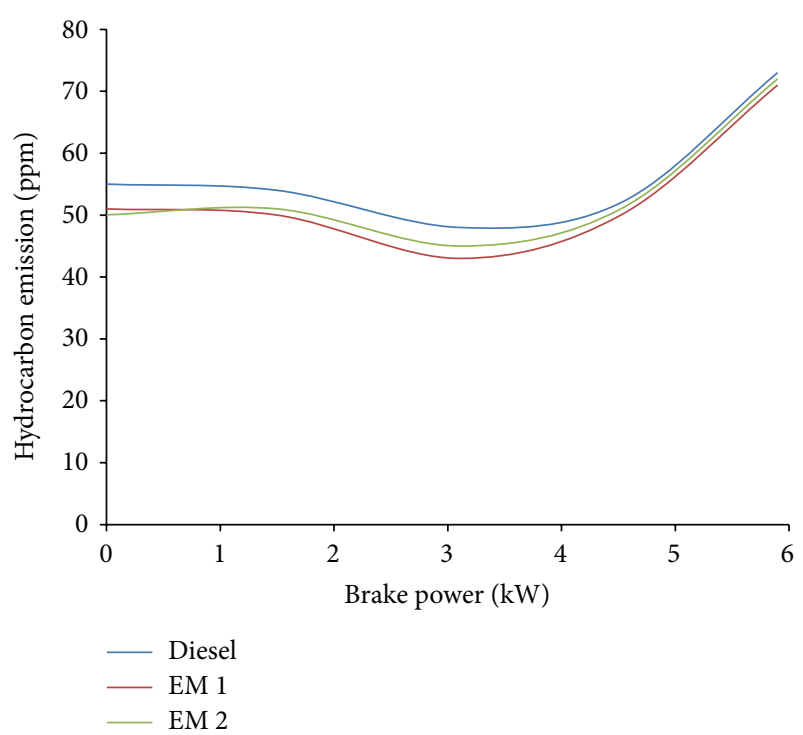

FIGURE 3: Brake power versus hydrocarbon (HC) emission.

from emulsified fuel is more than that from petroleum diesel. Because of micro explosion, the oxidation rate of fuel droplets gets increased, resulting in less fuel consumption than petroleum diesel. Hence emulsified fuel combustion results in more brake thermal efficiency. Abu-Zaid [12] concluded from his investigation that $20 \%$ of water content improved brake thermal efficiency in single cylinder diesel engine. Hence, results obtained were on a par with the previous results. Water addition improved the combustion. It was due to the conversion of water into steam at high temperature and pressure. Walavalkar [13], in his thesis, stated that the presence of oil-water interface with very low interfacial tension which further leads to finer atomization of fuel during injection would be another reason for the improvement of combustion efficiency.

\subsection{Emission Parameters}

6.2.1. Hydrocarbon (HC) Emission. Figure 3 shows that presence of hydrocarbon (HC) in the exhaust gases decrease with the diesel-water emulsion at all loads, and it is lower than the reference fuel (petroleum diesel). Armas et al. [7] attributed in his research work that during the micro explosion there was violent disintegration of water from diesel due to their volatility difference, which further enhanced better fuel-air mixing, leading to reduction of soot and hydrocarbon. In this experimental investigation decrease of $10.41 \%$ and $6.25 \%$ of hydrocarbon emission was found with the test fuels EM 1 and EM 2, respectively. In a previous research Kannan and Udayakumar [5] concluded that increased amount of $\mathrm{OH}$ radicals from water dissociation also reduced the formation of soot because high radical concentration promoted carbon oxidation, thereby limiting carbon availability for the soot precursors.

6.2.2. Carbon Monoxide (CO) Emission. Ganesan [14] discussed that carbon monoxide (CO) emissions from engine 


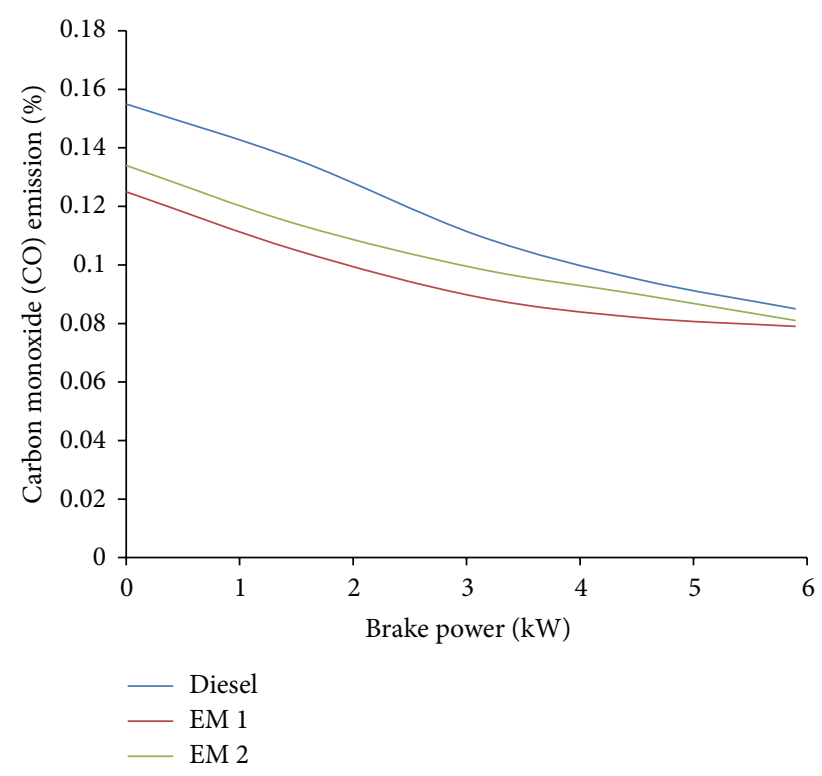

FIGURE 4: Brake power versus carbon monoxide (CO) emission.

exhaust were lower in the compression ignition engines when compared to spark ignition engines since the compression ignition is always being operated with lean mixture. Figure 4 shows that carbon monoxide emission is lower for all load conditions with diesel-water emulsion, when compared to petroleum diesel. In this experimental investigation it is observed that there is reduction of $7.05 \%$ and $4.71 \%$ of carbon monoxide emission with test fuels EM 1 and EM 2, respectively. The readings were compared at the maximum load condition.

Micro explosion of water droplets decreases the combustion zone temperature by adding the effect of oxygen for better combustion. It is in accordance with the previous research which states that the latent heat of water will cool the charge due to the evaporation of water and also the cylinder average temperature following injection and before ignition. In an earlier experimental investigation by Sudrajad et al. [8], it was reported that micro explosion of water reduced peak combustion temperature. He also had stated that the effect of adding water to the fuel would increase the oxygen availability in the fuel and result in lower $\mathrm{CO}$ emissions.

6.2.3. Smoke Opacity. Smoke opacity is strongly dependent on the amount of air in the cylinder as well as the oxygen content in the fuel. It was discussed by Canakci et al. [15] who stated that fuel composition affected the amount of smoke produced by an engine. Kumar et al. [16] mentioned that thermal cracking of molecules due to the high temperature led to soot formation. Figure 5 shows a reduction of smoke opacity emission of diesel-water emulsion and petroleum diesel fuel. There were reductions of $7.54 \%$ and $3.92 \%$ of smoke opacity emission when EM 1 and EM 2 test fuels were used. When water is vaporized, it absorbs the heat energy during combustion process, which leads to increase of ignition delay. In his research work, Kannan and Gounder [17]

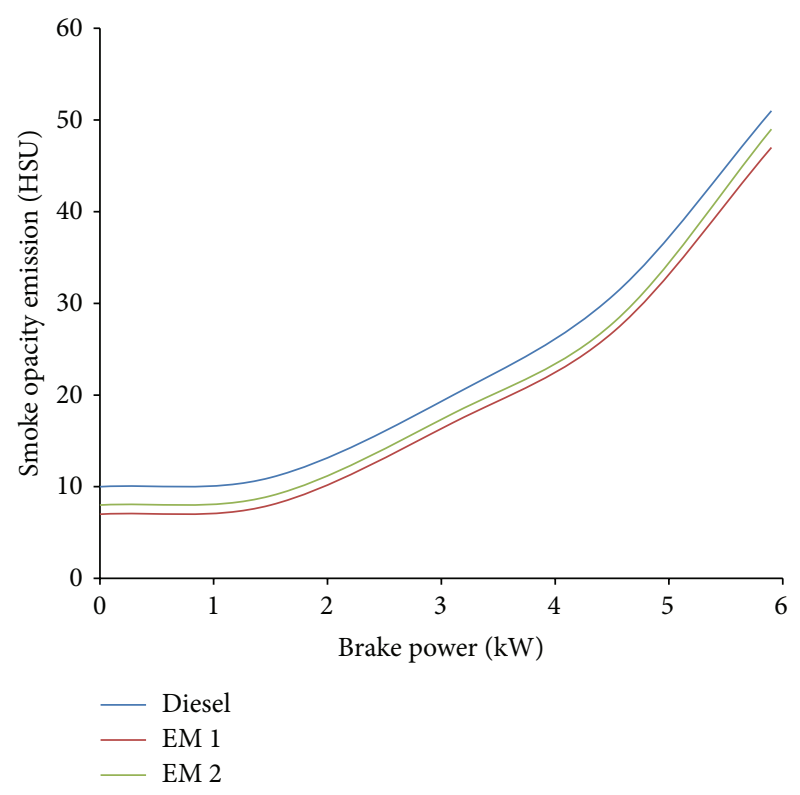

FIGURE 5: Brake power versus smoke opacity emission.

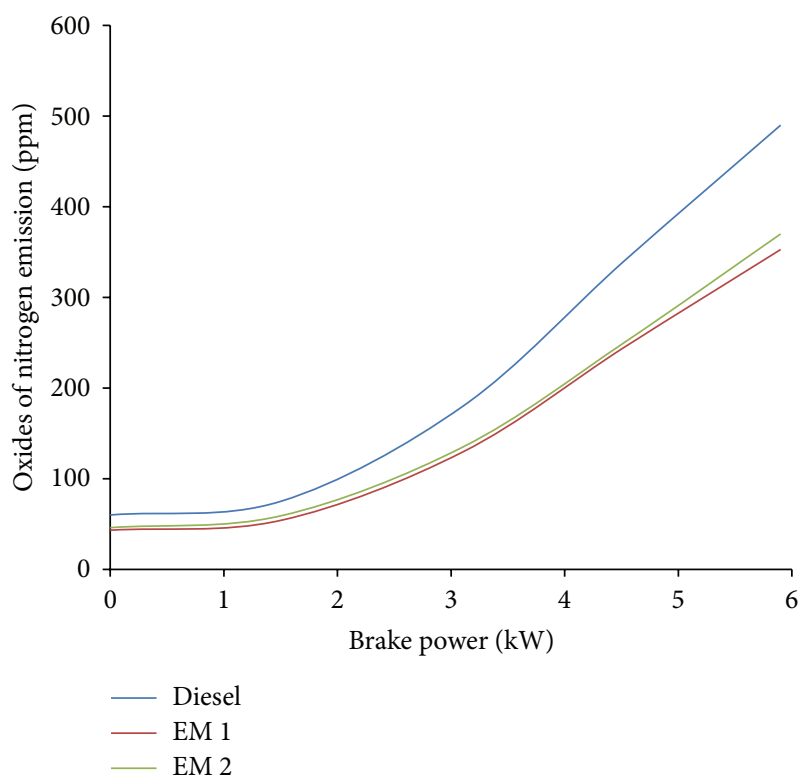

FIGURE 6: Brake power versus oxides of nitrogen emission.

discussed that the increase in delay period improved the mixing process which led to faster combustion reaction and hence the reduction of smoke opacity.

6.2.4. Oxides of Nitrogen $\left(\mathrm{NO}_{x}\right)$ Emission. Figure 6 shows that the oxides of nitrogen emission of diesel-water emulsion fuel are lesser than diesel. Musthafa et al. [18] showed that an increase in after combustion temperature caused an increase in $\mathrm{NO}_{x}$ emission. 
The work by Sudrajad et al. [8] showed that the presence of water in the fuel resulted in the following chemical reactions:

$$
\begin{gathered}
\mathrm{H}_{2} \mathrm{O}+\mathrm{O}=\mathrm{OH}+\mathrm{OH} \\
\mathrm{H}_{2} \mathrm{O}+\mathrm{H}=\mathrm{OH}+\mathrm{H}_{2} .
\end{gathered}
$$

See [8].

Duraisamy et al. [19] stated that the amount of $\mathrm{NO}_{x}$ produced is a function of the maximum temperature in the cylinder, oxygen concentrations, and residence time. The emission of $\mathrm{NO}_{x}$ was due to the chemical reaction between nitrogen and oxygen, which normally does not happen at the normal atmospheric pressure and temperature. But here due to the content of oxygen and elevated temperature during the combustion, the chemical reaction between oxygen and nitrogen took place. In this experimental investigation, it was observed that there were reductions of $28.52 \%$ and $24.48 \%$ with the test fuels EM 1 and EM 2, respectively.

\section{Conclusion}

The experimental investigation was carried out to compare the effect of addition of water for a quantity of $8 \%$ and $5 \%$ by volume to diesel. The test fuel EM 1 had a composition of $91 \%$ diesel, $8 \%$ water, $0.5 \%$ Tween 20 , and $0.5 \%$ Span 20 , while the test fuel EM 2 had a composition of 94\% diesel, 5\% water, $0.5 \%$ Tween 20, and $0.5 \%$ Span 20. All the results showed the increase or decrease in the parameter with reference to diesel fuel.

(i) With the test fuels EM 1 and EM 2, there was an increase in brake thermal efficiency for a percentage of 4.59 and 2.48, respectively.

(ii) Hydrocarbon emission decreased for a percentage of 10.41 and 6.25 with the fuels EM 1 and EM 2, respectively.

(iii) The smoke opacity decreased for a percentage of 7.54 and 3.92 with the fuels EM 1 and EM 2, respectively.

(iv) A drastic decrease of oxides of nitrogen was found. The decreased values were $28.52 \%$ and $24.48 \%$ with the emulsified fuels EM 1 and EM 2, respectively.

To conclude, simultaneous reduction of smoke opacity and $\mathrm{NO}_{x}$ was observed through this experimental investigation. Though the increase in brake thermal efficiency was very less, it could be improved further by adding fuel additives such as diethyl ether (DEE). In this experimental investigation, stability of the diesel water emulsion was checked for 8 hours; hence, the study could be extended for increasing the stability (to avoid separation) with suitable chemical additives.

\section{Scope of Future Work}

The experiment was mainly focused on the emission parameters and observed that simultaneous reduction of $\mathrm{NO}_{x}$ and smoke was a remarkable outcome in this investigation.
Present day researches are more about the use of various biodiesel fuels. In most of the researches, it is reported that $\mathrm{NO}_{x}$ emission is more in almost all biodiesel fuels. Hence this experimental work may be extended with biodiesel emulsion and inlet manifold water injection. For further improvement of brake thermal efficiency, diethyl ether (DEE) could be added with fuel.

\section{Acknowledgment}

The author sincerely thanks Dr. K. Annamalai, Ph.D., Assistant Professor, Department of Automobile Engineering, Anna University (MIT Campus), for his valuable guidance throughout the experimental investigation. The authors also thank Dr. V. P. Ramamoorthy, former Professor of Anna University and present Managing Trustee of Dhanalakshmi College of Engineering, for his motivation and support for the successful presentation of this paper.

\section{References}

[1] D. H. Cook and C. K. Law, "Preliminary study on the utilization of water-in-oil emulsions in diesel engine," Combustion Science and Technology, vol. 18, no. 5-6, pp. 217-221, 1978.

[2] D. W. Naegeli and C. A. Moses, "Fuel microemulsions for jet engine smoke reduction," Journal of Engineering for Power, vol. 105, no. 1, pp. 18-23, 1983.

[3] T. D. Daly and P. Nag, "Combustion modeling of soot reduction in diesel and alternate fuels using CHEMKIN," SAE Paper 200101-1239, SAE World Congress, Detroit, Mich, USA, 2001.

[4] J. C. Chadwell, J. G. Philip, and Dingle, "SAE technical paper series," Tech. Rep. 2008-01-1190, World Congress, Detroit, Mich, USA, 2008.

[5] K. Kannan and M. Udayakumar, "NOx and HC emission control using water emulsified diesel in single cylinder diesel engine," Journal of Engineering and Applied Sciences, vol. 4, no. 8, pp. 59-62, 2009.

[6] J. Ghojel, D. Honnery, and K. Al-Khaleefi, "Performance, emissions and heat release characteristics of direct injection diesel engine operating on diesel oil emulsion," Applied Thermal Engineering, vol. 26, no. 17-18, pp. 2132-2141, 2006.

[7] O. Armas, R. Ballesteros, F. J. Martos, and J. R. Agudelo, "Characterization of light duty Diesel engine pollutant emissions using water-emulsified fuel," Fuel, vol. 84, no. 7-8, pp. 1011-1018, 2005.

[8] A. Sudrajad, F. Hirotsugu, and I. Ali, "Experimental study of exhaust emissions of W/O emulsion fuel in DI single cylinder diesel engine," Modern Applied Science, vol. 5, no. 5, pp. 73-79, 2011.

[9] M. T. Ghannam and M. Y. E. Selim, "Stability behavior of waterin-diesel fuel emulsion," Petroleum Science and Technology, vol. 27, no. 4, pp. 396-411, 2009.

[10] P. Sherman, Encyclopedia of Emulsion Technology, vol. 1, Dekker, New York, NY, USA, 1983.

[11] A. Jankowski, "Influence of chosen parameters of water fuel micro emulsion on combustion processes, emission level of nitrogen oxides and fuel consumption of CI engine," Journal of KONES Powertrain and Transport, vol. 18, no. 4, pp. 593-600, 2011. 
[12] M. Abu-Zaid, "Performance of single cylinder, direct injection Diesel engine using water fuel emulsions," Energy Conversion and Management, vol. 45, no. 5, pp. 697-705, 2004.

[13] A. Y. Walavalkar, Combustion of water-in-oil emulsions of diesel and fresh and weathered crude oils floating on water, Pennsylvania State University, Pennsylvania, Pa, USA, 2001.

[14] V. Ganesan, Internal Combustion Engines, Tata McGraw-Hill, New Delhi, India, 2011.

[15] M. Canakci, A. N. Ozsezen, E. Arcaklioglu, and A. Erdil, "Prediction of performance and exhaust emissions of a diesel engine fueled with biodiesel produced from waste frying palm oil," Expert Systems with Applications, vol. 36, no. 5, pp. 9268-9280, 2009.

[16] A. R. Pradeep Kumar, K. Annamalai, and S. R. Premkartikkumar, "Experimental investigation on emission parameters of transesterified adelfa oil (Methyl Ester Of Nerium Oil)," International Journal of ChemTech Research, vol. 5, no. 4, pp. 1664-1670, 2013.

[17] T. K. Kannan and M. Rakkiyanna Gounder, "Thevetia peruviana biodiesel emulsion used as a fuel in a single cylinder diesel engine reduces NOx and smoke," Thermal Science, vol. 15, no. 4, pp. 1185-1191, 2011.

[18] I. M. Mohamed Musthafa, S. P. Sivapirakasam, and M. Udaya kumar, "Performance and emission characteristics of LHR CI engine fueled with rice bran oil as Biodiesel," International Journal of Recent Trends in Engineering and Technology, vol. 3, pp. 1-5, 2010.

[19] M. K. Duraisamy, T. Balusamy, and T. Senthilkumar, "Effect of compression ratio on $\mathrm{CI}$ engine fueled with methyl ester of thevetia peruviana seed oil," ARPN Journal of Engineering and Applied Sciences, vol. 7, no. 2, pp. 229-232, 2012. 

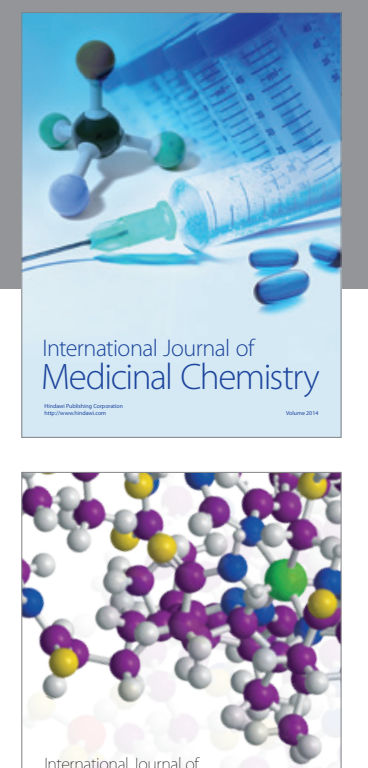

\section{Carbohydrate} Chemistry

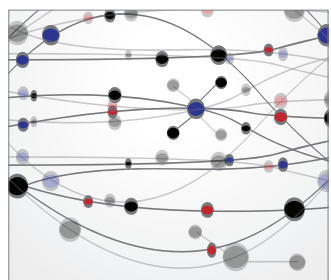

The Scientific World Journal
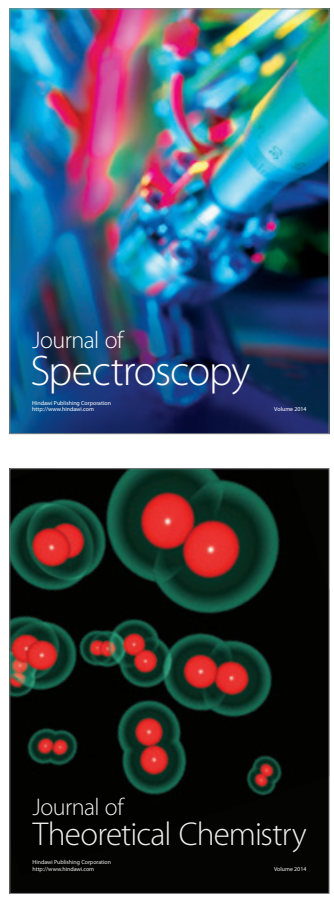
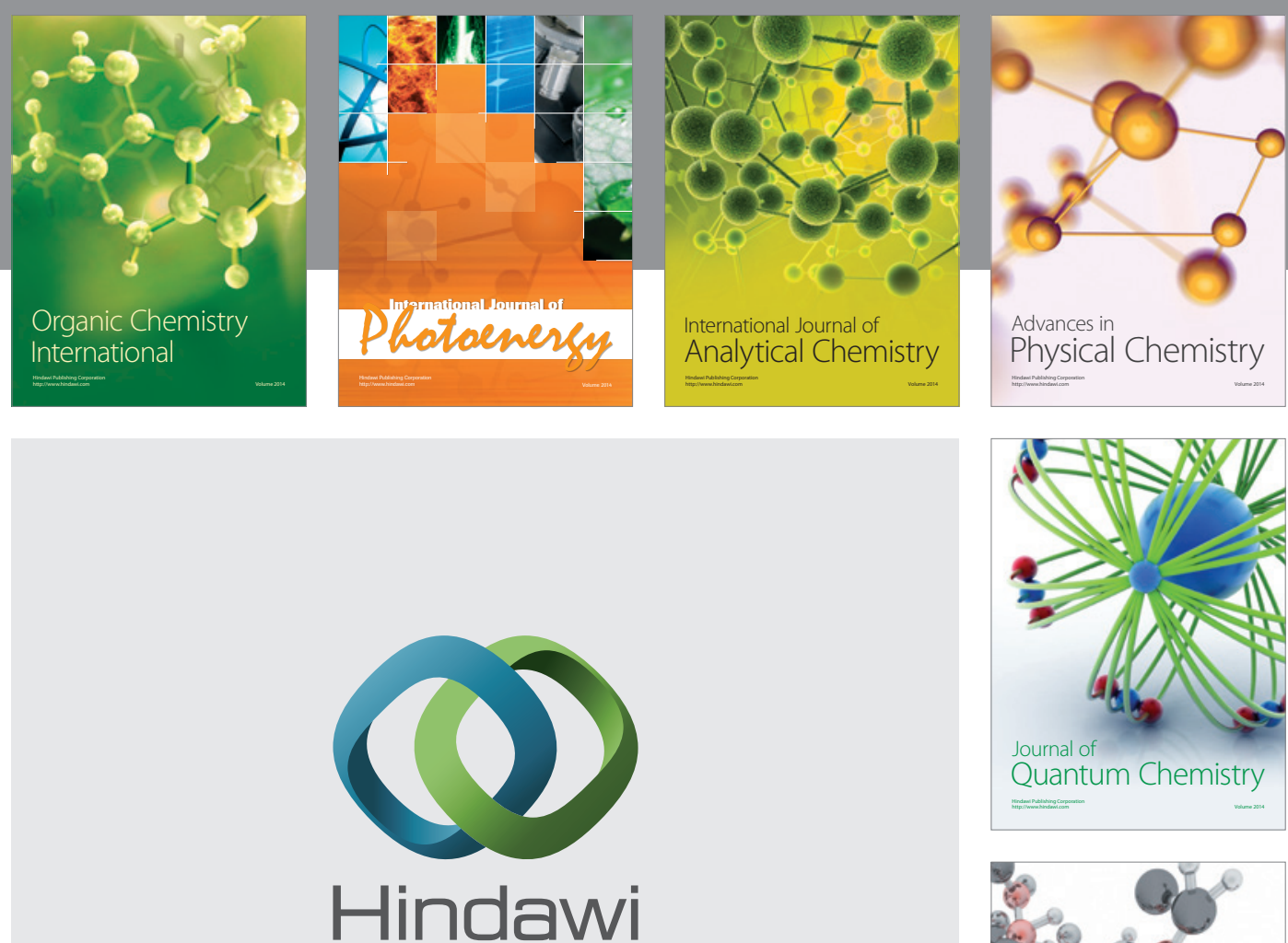

Submit your manuscripts at

http://www.hindawi.com

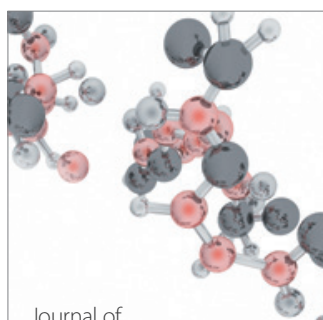

Analytical Methods

in Chemistry

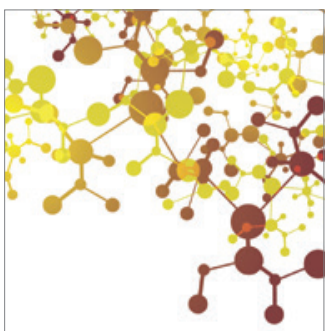

Journal of

Applied Chemistry

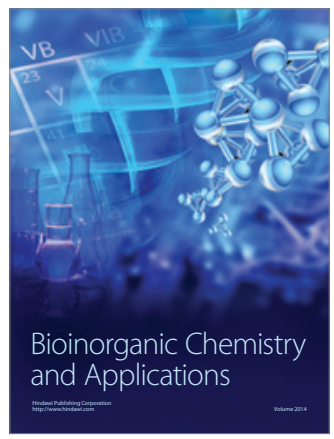

Inorganic Chemistry
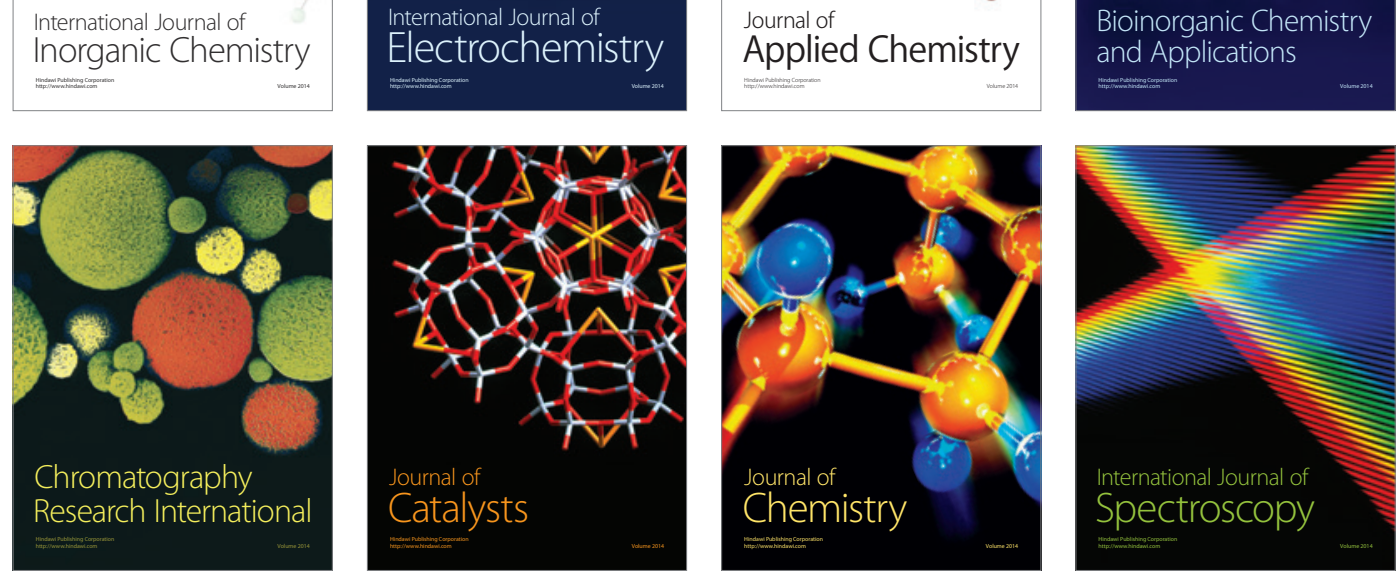